\title{
Componentes corporais de caprinos jovens $3 / 4$ Boer submetidos a dietas com óleo de licuri (Syagrus coronata)
}

[Body components of young crossbred Boer goats fed licury oil (Syagrus coronata) in the diet]

\author{
T.M. Silva ${ }^{1}$, R.L. Oliveira ${ }^{2,5}$, L.P. Barbosa ${ }^{3 *}$, A.F. Garcez Neto ${ }^{4}$, A.R. Bagaldo ${ }^{3}$, I.B. Jesus ${ }^{2}$, \\ F.M. Macome $^{2}$, C.V.D.M. Ribeiro ${ }^{2}$ \\ ${ }^{1}$ Centro de Ciências Agrárias - UFPB - Areias, PB. \\ ${ }^{2}$ Escola de Medicina Veterinária - UFBA \\ Av. Adhemar de Barros, s/n \\ 40170-110 - Salvador, BA \\ ${ }^{3}$ Universidade Federal do Recôncavo da Bahia - Cruz das Almas, BA \\ ${ }^{4}$ Universidade Federal do Paraná, Palotina, PR
}

\begin{abstract}
RESUMO
Determinou-se o melhor teor de óleo de licuri na dieta por intermédio das características dos componentes corporais de caprinos jovens $3 / 4$ Boer. Foram utilizados 19 caprinos inteiros, com média de idade inicial de três meses e média de peso de 10,8kg. Os animais foram alimentados com feno de Tifton-85 e mistura concentrada com 0; 1,5; 3,0 e 4,5\% de óleo de licuri. O experimento durou 60 dias; no último dia, os animais foram abatidos para avaliação das características dos componentes do peso corporal. O peso corporal ao abate, o peso de carcaça fria, o rendimento comercial, o rendimento de frigorificação, a área de olho de lombo, a proporção músculo:osso, os índices de compacidade de medidas biométricas, o peso dos cortes comerciais e o rendimento das vísceras comestíveis não carcaça não foram influenciados pela adição do óleo de licuri à dieta. O peso das vísceras comestíveis não carcaça e o índice de musculosidade do pernil sofreram influência negativa da adição do óleo na dieta. O óleo de licuri pode ser adicionado na dieta de caprinos jovens 3/4 Boer até 4,5\%, sem causar alterações significativas na carcaça.
\end{abstract}

Palavras-chave: caprino, biometria, carcaça, lipídio, musculosidade

\begin{abstract}
The best level of licury oil in the diet was evaluated by meat compounds of male young 3/4 Boer goats. Nineteen goats were used, with initial weight of $10.8 \mathrm{~kg} / \mathrm{LW}$. The animals were fed Tifton-85 hay and concentrated mix with $0.0,1.5,3.0$, and $4.5 \%$ of licury oil. The experiment lasted 60 days and, on the last day, the animals were submitted to feed fasting and slaughtered, in order to evaluate the characteristics of the live weight components. The body weight at slaughter, carcass weight, commercial yield, freezing yield, loin eye area, muscle-bone ratio, compactness carcass index, biometric measurements, commercial cuts weights, and edible viscera yield were not influenced by the licury oil added to the diet. The edible viscera weight and ham muscularity index were negatively influenced by the oil. Then, it could be added to diet of young $3 / 4$ Boer goats up to $4.5 \%$ without causing significant changes in the carcass.
\end{abstract}

Keywords: goat, biometry, carcass, lipids, muscularity

\section{INTRODUÇÃO}

No sistema de produção de caprinos para corte, as características quantitativas da carcaça são fundamentais, pois representam a fração de

Recebido em 2 de abril de 2009

Aceito em 11 de outubro de 2010

*Autor para correspondência (corresponding author)

E-mail:Ipires73@yahoo.com maior valor comercial. Desse modo, a avaliação dessas características é importante para que se possa identificar e priorizar animais com melhor carcaça. Outros componentes corporais, como as vísceras comestíveis, podem ser aproveitados para o consumo humano em pratos tradicionais 
no Nordeste (Medeiros et al., 2008). As vísceras comestíveis também são denominadas de não componentes da carcaça e geralmente são compostas pelo rúmen, retículo, omaso, abomaso, intestinos, pulmões, coração, fígado, baço, rins e língua, além de outros órgãos e vísceras (Rosa et al., 2002; Santos et al., 2005; Monte et al., 2007).

Existem fatores determinantes das características qualitativas e quantitativas da carcaça, tais como raça, sexo, idade e nutrição (Costa et al., 2008). Dentre esses fatores, vários podem afetar o rendimento de carcaça, sobretudo a alimentação (Alves et al., 2003).

Lipídios são utilizados na alimentação de ruminantes com o intuito de aumentar a densidade energética da dieta, a eficiência alimentar e, consequentemente, o desempenho dos animais. Alves et al. (2003) e Almeida et al. (2009) verificaram que dietas mais energéticas podem aumentar o peso e o rendimento da carcaça.

Dentre as muitas fontes de lipídios, o óleo de licuri pode representar uma alternativa na alimentação de ruminantes. Este óleo é obtido do fruto de uma palmeira - Syagrus coronata (Martius) Beccari -, nativa da região semiárida do Nordeste brasileiro. A coleta e a comercialização desse fruto representam importante fonte de renda para a população dessa região. A utilização de seu óleo tem se restringido apenas à fabricação de cosméticos e saponáceos, enquanto, na alimentação animal, ainda não foi suficientemente estudada.

Este trabalho foi realizado com o objetivo de determinar o melhor teor de óleo de licuri na dieta de caprinos jovens $3 / 4$ Boer por intermédio das características da carcaça e dos não componentes da carcaça.

\section{MATERIAL E MÉTODOS}

O experimento foi realizado entre outubro e dezembro de 2007. Foram utilizados 19 cabritos 3/4 Boer, não castrados, vacinados e vermifugados, com média de 90 dias de idade e média de peso inicial de $10,8 \pm 2,00 \mathrm{~kg}$. Os animais foram alojados, individualmente, em baias de 1,0x1,0m, com piso suspenso de madeira ripada, providas de bebedouros e comedouros.

O experimento durou 60 dias e foi precedido por 15 dias de adaptação dos animais ao ambiente, ao manejo e a dietas. Os cabritos receberam, duas vezes ao dia, dietas com proporção volumoso:concentrado de 50:50, na forma de mistura completa. O concentrado foi composto de farelo de milho, farelo de soja, sal mineral e óleo de licuri, nos teores de 0,$0 ; 1,5 ; 3,0$ e 4,5\% da matéria seca (Tab. 1). Foram utilizados cinco animais para cada tratamento, exceto no tratamento com 4,5\% de óleo, que utilizou quatro animais. Como volumoso, usou-se o feno de Tifton-85 (Cynodon sp.) moído em partículas de aproximadamente $5 \mathrm{~cm}$. A oferta de alimento foi feita de forma a garantir entre $10 \%$ e $20 \%$ de sobras. O fornecimento de água foi ad libitum.

A composição bromatológica dos ingredientes das dietas (Tab. 2) foi feita conforme AOAC (Official..., 1990) para determinação dos teores de matéria seca (MS), matéria mineral (MM), proteína bruta $(\mathrm{PB})$ e extrato etéreo (EE). As análises para a determinação da fibra em detergente neutro (FDN) e fibra em detergente ácido (FDA) lignina, celulose e hemiceluloses foram feitas segundo Van Soest et al. (1991). Os carboidratos não fibrosos foram calculados de acordo com Mertens (1997). Entre o $40^{\circ}$ e o $42^{\circ}$ dia do experimento, foram quantificadas e coletadas fezes (coleta total com bolsas apropriadas) e sobras para determinação do consumo e da digestibilidade dos nutrientes. Os teores de nutrientes digestíveis totais (NDT) das dietas foram obtidos por meio da soma das frações digestíveis (EE digestível foi multiplicado por 2,25).

Ao final do período experimental, os animais, com aproximadamente cinco meses de idade, foram submetidos a jejum por 12 horas e, em seguida, pesados para determinação do peso corporal ao abate (PCA); posteriormente, os animais foram insensibilizados (eletronarcose), e finalmente foram realizadas a sangria, a esfola e a evisceração. 
Silva et al.

Tabela 1. Proporção dos ingredientes e composição química das dietas experimentais utilizadas na alimentação de caprinos 3/4 Boer

\begin{tabular}{lrrrr}
\hline \multirow{2}{*}{ Ingrediente (\% MS) } & \multicolumn{3}{c}{ Óleo de licuri (\%MS) } \\
\cline { 2 - 5 } & 0,00 & 1,50 & 3,00 & 4,50 \\
\hline Farelo de milho & 34,12 & 32,30 & 30,40 & 28,70 \\
Farelo de soja & 13,28 & 13,60 & 14,00 & 14,20 \\
Óleo de licuri $^{1}$ & 0,00 & 1,50 & 3,00 & 4,50 \\
Premix mineral $^{1}$ & 2,60 & 2,60 & 2,60 & 2,60 \\
Feno de Tifton-85 $_{\text {Composição química }}^{50,00}$ & 50,00 & 50,00 & 50,00 \\
\hline Matéria seca (\%) & & & 89,84 & 90,01 \\
Matéria mineral (\% MS) & 89,52 & 89,68 & 7,53 & 7,53 \\
Proteína bruta (\% MS) & 7,54 & 7,53 & 10,87 & 10,86 \\
Extrato etéreo (\% MS) & 10,79 & 10,81 & 6,20 & 7,61 \\
Fibra em detergente neutro (\% MS) & 3,37 & 4,78 & 42,92 & 42,74 \\
Fibra em detergente ácido (\% MS) & 43,29 & 43,10 & 24,61 & 24,55 \\
Lignina (\% MS) & 24,71 & 24,66 & 4,24 & 4,22 \\
Celulose (\% MS) & 4,30 & 4,27 & 20,37 & 20,33 \\
Hemiceluloses (\% MS) & 20,41 & 20,39 & 18,31 & 18,19 \\
Carboidratos não fibrosos (\% MS) & 18,58 & 18,44 & 32,48 & 31,47 \\
Nutrientes digestíveis totais (\% MS) & 35,03 & 33,77 & 75,30 & 80,60 \\
\hline
\end{tabular}

${ }^{1}$ Níveis de garantia por kg= cálcio: $120 \mathrm{~g}$; fósforo: 87g; sódio: 147g; enxofre: 18g; cobre: 590mg; cobalto: 40mg; cromo: 20mg; ferro: 1800mg; iodo: 80mg; manganês: 1300mg; selênio: 15mg; zinco: 3800mg; molibdênio: 300mg; flúor máximo: 870mg; Solubilidade do fósforo (P) em ácido cítrico a 2\% mínimo - 95\%.

Tabela 2. Composição bromatológica dos ingredientes das dietas experimentais utilizadas na alimentação de caprinos $3 / 4$ Boer

\begin{tabular}{lrrrc}
\hline Composição & $\begin{array}{c}\text { Farelo de } \\
\text { milho }\end{array}$ & $\begin{array}{c}\text { Farelo de } \\
\text { soja }\end{array}$ & $\begin{array}{c}\text { Feno de } \\
\text { Tifton-85 }\end{array}$ & Óleo de licuri \\
\hline Matéria seca (\%) & 88,91 & 88,51 & 89,64 & 100,00 \\
Matéria mineral (\% MS) & 1,54 & 6,51 & 6,51 & - \\
Proteína bruta (\% MS) & 5,88 & 42,92 & 6,16 & - \\
Extrato etéreo (\% MS) & 5,41 & 3,52 & 2,12 & 100,00 \\
Fibra em detergente neutro (\% MS) & 11,84 & 10,76 & 75,63 & - \\
Fibra em detergente ácido (\% MS) & 4,44 & 8,05 & 44,26 & - \\
Lignina (\% MS) & 1,63 & 0,39 & 7,39 & - \\
Celulose (\% MS) & 2,81 & 7,66 & 36,87 & - \\
Hemiceluloses (\% MS) & 7,40 & 2,71 & 31,37 & - \\
Carboidratos não fibrosos (\% MS) & 75,34 & 36,29 & 9,58 & - \\
\hline
\end{tabular}

O sangue foi coletado e pesado. As vísceras foram pesadas individualmente, cheias e vazias, para determinação do conteúdo gastrintestinal (CTGI) e do peso do corpo vazio (PCVz), que é o peso corporal ao abate menos o peso do conteúdo gastrintestinal.

Os pesos dos órgãos e vísceras comestíveis fígado, rins, aparelho respiratório, língua, coração, estômagos e intestinos - foram somados para determinação dos não componentes da caraça para cálculo do seu rendimento percentual em relação ao peso corporal ao abate.
Após a retirada da cabeça e patas, foi feita a avaliação das características biométricas segundo Yañez et al. (2004), a saber: comprimento interno da carcaça - distância entre o bordo anterior do osso púbis e o bordo anterior da primeira costela em seu ponto médio -, comprimento externo da carcaça - distância entre a articulação cervicotorácica e a primeira articulação intercoccígea -, comprimento da perna - distância entre o trocânter maior do fêmur e o bordo da articulação tarsometatarsiana -, perímetro da garupa - perímetro na região da garupa, com base nos trocânteres dos fêmures -, 
perímetro de pernil - perímetro tomando como base a parte média da perna, acima da articulação fêmuro-tíbio-patelar -, e perímetro do tórax perímetro medido atrás da paleta.

As carcaças permaneceram em câmara fria a $4^{\circ} \mathrm{C}$ por 24 horas; foram pesadas para determinação do peso de carcaça fria (PCF) e, em seguida, cortadas entre a $12^{\mathrm{a}}$ e $13^{\mathrm{a}}$ costelas para determinação da área de olho de lombo (AOL), que foi feita usando folha de transparência e caneta apropriada. A AOL foi determinada em $\mathrm{cm}^{2}$ após a digitalização das imagens.

A meia-carcaça esquerda foi subdividida em cinco regiões anatômicas, as quais foram pesadas individualmente, para obtenção das porcentagens que representavam em relação ao peso da carcaça fria. As regiões anatômicas foram: pescoço - entre a primeira e a sétima vértebra cervical -, paleta - base óssea:escápula, úmero e carpo -, costelas - entre a primeira e a $13^{\mathrm{a}}$ vértebra torácica -, lombo - músculo longissimus dorsi dissecado dos ossos vertebrais - e pernil - secção entre a última vértebra lombar e a primeira sacra. Este procedimento foi adaptado de Colomer- Rocher et al. (1987).

Foi calculado o índice de compacidade da carcaça - peso da carcaça fria dividido pelo comprimento interno da carcaça -, segundo Yañez et al. (2004), e determinaram-se o rendimento comercial da carcaça $(\mathrm{RCC}=\mathrm{PCF} /$ PVA x 100) e o rendimento de frigorificação (RF $=\mathrm{PCF} / \mathrm{PCVz} \times 100)$.
O índice de musculosidade do pernil e a proporção músculo:osso foram determinados após dissecação e pesagem dos músculos que recobrem o fêmur - bíceps femoral, semitendinoso, adutor, semimembranoso e quadríceps femoral e do fêmur completamente limpo. Para isso, utilizou-se a fórmula descrita por Purchas et al. (1991): índice de musculosidade $=\left[(\mathrm{PM} 5 / \mathrm{CF})^{\mathbf{0 , 5}} / \mathrm{CF}\right]$, em que PM5 é o peso (g) dos cinco músculos e CF é o comprimento $(\mathrm{cm})$ do fêmur. A proporção músculo:osso foi obtida dividindo-se o peso dos cinco músculos citados (PM5) pelo peso do fêmur.

O delineamento experimental utilizado foi inteiramente ao acaso, e os dados obtidos foram avaliados por meio de análise de variância e teste de regressão, com 5\% de significância; o peso inicial foi utilizado como covariável e o software utilizado foi o SPSS $13.0^{\circledR}$.

\section{RESULTADOS E DISCUSSÃO}

A adição de óleo à dieta resultou em aumento do teor de NDT das dietas experimentais (Tab. 1). Contudo, esse aumento não resultou em maior peso e rendimento de carcaça dos animais (Tab. 3), diferente dos experimentos de Alves et al. (2003) e Ryan et al. (2007), os quais verificaram influência da dieta sobre as características de carcaça de ovinos e caprinos, respectivamente.

Tabela 3. Características de carcaça de caprinos jovens 3/4 Boer submetidos a dietas com óleo de licuri

\begin{tabular}{|c|c|c|c|c|c|}
\hline \multirow{2}{*}{ Item } & \multicolumn{4}{|c|}{ Teor de óleo de licuri (\%) } & \multirow{2}{*}{ CV (\%) } \\
\hline & 0,00 & 1,50 & 3,00 & 4,50 & \\
\hline \multicolumn{6}{|l|}{ Pesos (kg) } \\
\hline Corporal ao abate & 13,64 & 13,36 & 13,40 & 11,98 & 19,26 \\
\hline Carcaça fria & 5,92 & 5,80 & 5,44 & 4,80 & 21,96 \\
\hline \multicolumn{6}{|l|}{ Rendimentos (\%) } \\
\hline Comercial da carcaça & 43,39 & 43,22 & 40,63 & 40,52 & 9,83 \\
\hline Frigorificação & 56,10 & 57,47 & 53,98 & 57,99 & 14,23 \\
\hline Não componentes da carcaça & 14,14 & 12,58 & 11,99 & 12,94 & 14,18 \\
\hline Área de olho de lombo $\left(\mathrm{cm}^{2}\right)$ & 6,46 & 6,93 & 6,49 & 5,39 & 21,03 \\
\hline Proporção músculo: osso & 4,70 & 4,59 & 4,37 & 4,48 & 12,09 \\
\hline
\end{tabular}

O aumento do teor energético de uma dieta não necessariamente representa maior aporte energético ao animal, pois, para que o acréscimo de NDT na dieta proporcione diferenças nas características de carcaça, este aumento deve ser acompanhado de maior consumo de NDT. Sabese que o aumento da concentração energética da dieta por adição de lipídios pode comprometer a 
degradação de carboidratos fibrosos e, consequentemente, a ingestão de MS (Jenkins e McGuire, 2006). Assim, o aumento da densidade energética por meio da adição de óleo de licuri pode ter sido acompanhado de redução no consumo de MS, fato que, provavelmente, impediu o aumento do consumo de energia pelos animais.

Os pesos corporal ao abate e da carcaça fria, e o rendimento comercial da carcaça foram mais baixos que os encontrados por Dias et al. (2008) e Amorim et al. (2008), que também estudaram o efeito da dieta sobre as características de carcaça de cabritos abatidos entre seis e 10 meses de idade. Vale lembrar, contudo, que ao abate, no presente trabalho, os animais eram mais jovens, portanto mais leves, e sabe-se que animais mais jovens apresentam maior proporção de vísceras em relação à carcaça. Os tecidos que compõem a carcaça são de desenvolvimento mais lento que os tecidos viscerais, logo, sua proporção em relação aos outros constituintes corporais é menor em animais mais jovens (Rosa et al., 2002; Owens et al., 1993). Apesar de apresentarem menor peso de carcaça, caprinos abatidos precocemente - entre quatro e cinco meses de idade - possuem carne com maior aceitabilidade pelo consumidor. Smith et al. (1978), Madruga et al. (2002) e Dhanda et al. (2003) relataram que quanto mais jovens mais apetecível é a carne dos animais. Portanto, a redução na quantidade de carne produzida pode ser compensada pela produção de carne com melhor qualidade.

O índice de musculosidade do pernil sofreu influência negativa à adição de óleo de licuri na dieta (Fig. 1). Tal fato leva a crer que o efeito da dieta foi somente na conformação e não na constituição da perna, pois não houve alteração na proporção músculo e osso do pernil.

A redução de peso dos não componentes da carcaça (Fig. 2) em razão da adição de óleo de licuri na dieta pode estar relacionada ao aumento da concentração energética da dieta e ao provável aumento da digestibilidade de matéria seca, segundo Silva et al. (2008), com o acréscimo do óleo na dieta.

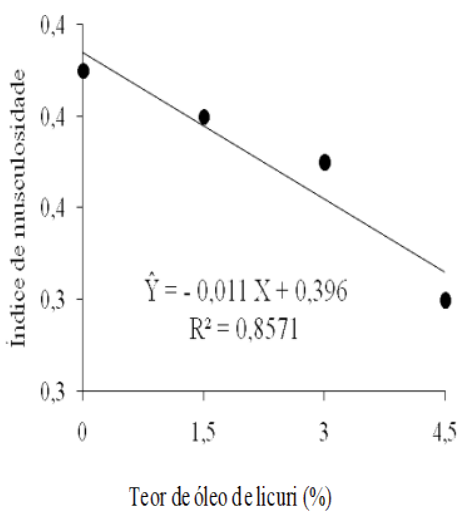

Figura 1. Índice de musculosidade do pernil de caprinos jovens $3 / 4$ Boer submetidos a dietas com níveis de óleo de licuri.

Segundo Alves et al. (2003), dietas com teores mais altos de energia e maior digestibilidade apresentam menor tempo de retenção no trato gastrintestinal e, consequentemente, menor desenvolvimento dos órgãos envolvidos nos processos digestivos. A redução de peso dos não componentes da carcaça sem aumento da proporção da carcaça é indesejável, pois, apesar de esses componentes não serem considerados nobres, representam fonte adicional de renda para o produtor e, muitas vezes, são utilizados para cobrir os custos referentes ao abate do animal, além de representarem um alimento com composição química comparável à da carne (Costa et al. 1999; Santos et al., 2005).

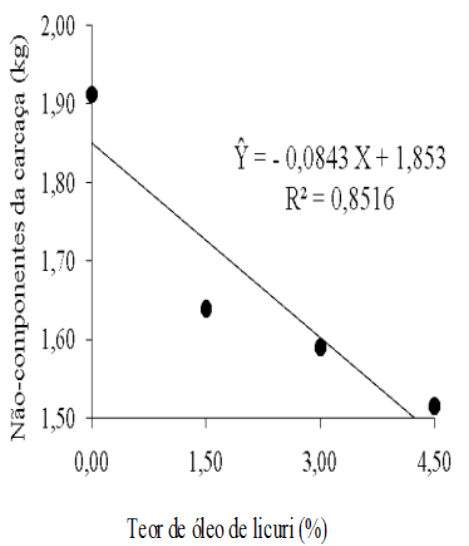

Figura 2. Peso (kg) dos não componentes da carcaça de caprinos jovens $3 / 4$ Boer submetidos a dietas com óleo de licuri. 
O preço pago por quilograma de não componentes da carcaça foi de $\mathrm{R} \$ 3,00$ e, com base nesse valor, cada $1 \%$ de óleo de licuri adicionado à dieta representou redução no preço pago de, aproximadamente, $\mathrm{R} \$ 0,25$ por animal abatido. Sabe-se, entretanto, que alguns abatedouros pagam ao produtor tendo por base o peso corporal ao abate ou o peso da carcaça, sem contabilizar o peso dos não componentes.
As medidas biométricas, o índice de compacidade da carcaça e os pesos e proporções dos cortes comerciais não diferiram entre os tratamentos (Tab. 4 e 5), provavelmente porque os tratamentos não influenciaram no peso corporal ao abate. Isso está relacionado à harmonia anatômica citada por Boccard e Drumond (1960), segundo a qual, em carcaças de pesos e quantidades de gordura similares, praticamente todas as regiões corporais se encontram em proporções semelhantes.

Tabela 4. Biometria da carcaça e índices de compacidade em caprinos jovens $3 / 4$ Boer submetidos a dietas com óleo de licuri

\begin{tabular}{lrrrrr}
\hline \multicolumn{1}{c}{ Ítem } & \multicolumn{4}{c}{ Teor de óleo de licuri } & \multirow{2}{*}{ CV (\%) } \\
\cline { 2 - 5 } & 0,00 & 1,50 & 3,00 & 4,50 & 6,46 \\
\hline Comprimento externo (cm) & 43,60 & 43,60 & 43,60 & 41,75 & 5,94 \\
Comprimento interno (cm) & 42,20 & 42,00 & 42,60 & 40,50 & 4,41 \\
Comprimento do pernil (cm) & 30,20 & 29,80 & 29,00 & 29,25 & 9,45 \\
Perímetro do pernil (cm) & 23,20 & 24,20 & 22,60 & 21,50 & 12,04 \\
Perímetro da garupa (cm) & 40,00 & 37,00 & 35,40 & 36,00 & 6,43 \\
Perímetro do tórax (cm) & 51,20 & 51,20 & 51,00 & 50,00 & 16,47 \\
Índice de compacidade da carcaça $(\mathrm{kg} / \mathrm{cm})$ & 0,14 & 0,14 & 0,13 & 0,12 & \\
\hline
\end{tabular}

Tabela 5. Cortes comerciais das carcaças de caprinos jovens 3/4 Boer submetidos a dietas com óleo de licuri

\begin{tabular}{|c|c|c|c|c|c|}
\hline \multirow{2}{*}{ Corte } & \multicolumn{4}{|c|}{ Teor de óleo de licuri (\%) } & \multirow{2}{*}{ CV (\%) } \\
\hline & 0,00 & 1,50 & 3,00 & 4,50 & \\
\hline Paleta (g) & 647,00 & 636,00 & 611,00 & 538,75 & 20,46 \\
\hline Pescoço (g) & 464,00 & 477,00 & 442,00 & 377,5 & 17,90 \\
\hline Costela (g) & 687,00 & 668,00 & 571,00 & 500,00 & 28,46 \\
\hline Lombo (g) & 77,00 & 71,00 & 64,00 & 51,25 & 28,77 \\
\hline Pernil (g) & 901,00 & 883,00 & 853,00 & 738,75 & 21,31 \\
\hline Paleta (\%) & 21,94 & 22,05 & 22,47 & 22,45 & 3,31 \\
\hline Pescoço (\%) & 15,88 & 16,86 & 16,3 & 15,83 & 9,77 \\
\hline Costela (\%) & 23,14 & 22,68 & 20,82 & 20,74 & 8,07 \\
\hline Lombo (\%) & 02,59 & 02,46 & 02,34 & 02,10 & 13,10 \\
\hline Pernil (\%) & 30,47 & 30,72 & 31,25 & 30,73 & 3,86 \\
\hline
\end{tabular}

\section{CONCLUSÕES}

O óleo de licuri pode ser adicionado na dieta de caprinos jovens $3 / 4$ Boer até $4,5 \%$, sem causar alterações significativas na carcaça.

\section{REFERÊNCIAS BIBLIOGRÁFICAS}

ALMEIDA, T.R.V.; PÉREZ, J.R.O.; PAULA, O.J. et al. Efeito do nível de energia metabolizável na composição dos tecidos da carcaça de cordeiros da raça Santa Inês. Arq. Bras. Med. Vet. Zootec., v.61, p.1364-1372, 2009.
ALVES, K.S.; CARVALHO, F.F.R.; FERREIRA, M.A. et al. Níveis de energia em dietas para ovinos Santa Inês: características de carcaça e constituintes corporais. Rev. Bras. Zootec., v.32, supl.2, p.1927-1936, 2003.

AMORIM, G.L.; BATISTA, Â.M.V.; CARVALHO, F.F.R. et al. Substituição do milho por casca de soja: consumo, rendimento e características de carcaça e rendimento da buchada de caprinos. Acta Sci. Anim. Sci., v.30, p.41-49, 2008. 
BOCCARD, R.; DRUMOND, B. L. Estude de la production de la viande chez le ovins and variation de l'importance relative de differents régions corporelles de l'agneaus de boucgerie. In: ANNALES DE ZOOTECHINE, 9., 1960, Paris. Anais... Paris, 1960. p.355-365.

COLOMER-ROCHER, F.; MORAND-FEHR, P.; KIRTON, A.H. Standard methods and procedures for goat carcass evaluation, jointing and tissue separation. Livest. Prod. Sci., v.17, p.149-159, 1987.

COSTA, R.G.; CARTAXO, F.Q.; SANTOS N.M. et al. Carne caprina e ovina: composição lipídica e características sensoriais. Rev. Bras. Saúde Prod. Anim., v.9, p.497-506, 2008.

COSTA, J.C.C.; OSÓRIO, J.C.S.; SILVA, C.A.S. et al. Componentes do peso vivo em cordeiros não castrados. Rev. Bras. Agroc., v.5, p.42-44, 1999.

DHANDA, J.S.; TAYLOR, D.G.; MURRAY, P.J. Part 1. Growth, carcass and meat quality parameters of male goats: effects of genotype and liveweight at slaughter. Small Rumin. Res., v.50, p.57-66, 2003.

DIAS, A.M.A.; BATISTA, Â.M.V.; CARVALHO, F.F.R. et al. Características de carcaça e rendimento de buchada de caprinos alimentados com farelo grosso de trigo em substituição ao milho. Rev. Bras. Zootec., v.37, p.1280-1285, 2008.

JENKINS, T.C.; McGUIRE, M.A. Major advances in nutrition: impact on milk composition. J. Dairy Sci., v.89, p.1302-1310, 2006.

MADRUGA, M.S.; NARAIN, N.; ARRUDA, S.G.B. et al. Influência da idade de abate e da castração nas qualidades físico-químicas, sensoriais e aromáticas da carne caprina. Rev. Bras. Zootec., v.31, supl., p.1562-1570, 2002.

MEDEIROS, G.R.; CARVALHO, F.F.R.; FERREIRA, M.A. et al. Efeito dos níveis de concentrado sobre os componentes não carcaça de ovinos Morada Nova em confinamento. Rev. Bras. Zootec., p.1063-1071, 2008.

MERTENS, D. R. Creating a system for meeting the fiber requirements of dairy cows. J. Dairy Sci., v.80, p.1463-1481, 1997.
MONTE, A.L.S.; SELAIVE-VILLARROEL, A.B.; PÉREZ, J.R.O. et al. Rendimento de cortes comerciais e composição tecidual da carcaça de cabritos mestiços. Rev. Bras. Zootec., v.36, supl., p.2127-2133, 2007.

OFFICIAL methods of analysis. 15.ed. Washington, DC: AOAC 1990.

OWENS, F.N.; DUBESKI, P.; HANSON, C.F. Factors that alter the growth and development of ruminants. J. Anim. Sci., v.71, p.3152-3172, 1993.

PURCHAS, R.W.; DAVIES, A.S.; ABDULLAH, A.Y. An objective measure of muscularity: changes with animal growth and differences between genetic lines of southdown sheep. Meat Sci., v.30, p.81-94, 1991.

ROSA, G.T.; PIRES, C.C.; SILVA, J.H.S. et al. Proporções e coeficientes de crescimento dos não componentes da carcaça de cordeiros e cordeiras em diferentes métodos de alimentação. Rev. Bras. Zootec., v.31, p.2290-2298, 2002.

RYAN, S.M.; UNRUH, J.A.; CORRIGAN, J. et al. Effects of concentrate level on carcass traits of Boer crossbred goats. Small Ruminant Res., v.73, p.67-76, 2007.

SANTOS, N.M.; COSTA, R.G.; MEDEIROS, A.N. et al. Caracterização dos componentes comestíveis não constituintes da carcaça de caprinos e ovinos. Agropec. Tec., v.26, p.77-85, 2005

SILVA, T.M.; OLIVEIRA, R.L.; BARBOSA, L.P. et al. Digestibilidade dos nutrientes de dietas com níveis de óleo de licurí em caprinos 3/4 Boer. In: ZOOTEC, 18., 2008, João Pessoa. Anais... João Pessoa, 2008.

SMITH, G. C.; CARPENTER, Z. L.; SHELTON M. Effect of age and quality level on the palatability of goat meat. J. Anim. Sci., v.46, p.1229-1235, 1978.

VAN SOEST, P.J.; ROBERTSON, J.B.; LEWIS, B.A. Methods for dietary fiber, neutral detergent fiber, and nonstarch polyssacharides in relation to animal nutrition. J. Dairy Sci., v.74, p.35833597, 1991.

YÁÑEZ, E.A.; RESENDE, K.T.; FERREIRA, Â.C.D. et al. Utilização de medidas biométricas para predizer características da carcaça de cabritos Saanen. Rev. Bras. Zootec., v.33, p.1564-1572, 2004. 